\title{
Assessment of Food Safety in Hospital Kitchens in Tanta City Gharbia Governorate, Egypt
}

\section{Yasmeen Mohamed Elsersy, Asmaa Abdel-Raheem Omar, Nehal Salah EL- Deen Shehab El-Deen, Gamalat Mohamed Ali El-Saleet}

Public Health Preventive and Social Medicine, Faculty of Medicine, Tanta University, Egypt.

Received: January, 2016 Accepted: May, 2016

\begin{abstract}
:
Background: Food borne infections in health care settings have been represented as an important public health problem worldwide. They are a leading cause of morbidity and mortality and economic losses in both developed and developing countries. Objective: To assess food safety in hospital kitchens (university and other governmental hospital kitchens) in Tanta city, Gharbia Governorate, Egypt. Methods: A cross sectional study was conducted in 9 hospital kitchens ( 3 university kitchens and 6 governmental kitchens) and all food handlers in these kitchens (175) were included in the study. Two tools were modified by the researcher to collect the needed data. A Modified kitchen observational checklist and Food handlers' observational checklist were used. Results: All university kitchens had insufficient application of food safety measures in both morning and evening shifts. Regarding governmental kitchens food safety requirements; $40 \%$ were insufficient and $60 \%$ were somewhat sufficient in morning shift, but in the evening shift $60 \%$ of kitchens were insufficient and $40 \%$ of them were somewhat sufficient. The majority of both university and governmental food handlers had insufficient practice regarding application of food safety measures $(94.9 \%$ and $84.2 \%)$ respectively. Conclusion: Insufficient conduction of food safety measures in university and governmental hospital kitchens as well as insufficient application of food safety measures by food handlers were encountered putting patients are at risk of getting food borne infections.
\end{abstract}

Key words:, Assessment, Food, Safety, Kitchens, Hospitals, Egypt.

Corresponding author: asmaa.atallah@med.tanta.edu.eg

\section{Introduction:}

According to Food and Agricultural Organization (FAO), Food safety is defined as an assurance that food will not cause harm to consumers when it is prepared and/or eaten according to its intended use. ${ }^{1}$

Food borne diseases presents a widespread and growing public health problem both in developed and developing countries. ${ }^{2}$ In the last few years food borne outbreaks has increased particularly food poisoning which remains one of the most common causes of illness worldwide. ${ }^{3}$ In Egypt from May to March (2013), three food poisoning outbreaks were reported by Ministry of Health and Population (MOHP) among university students. ${ }^{4}$

Food borne diseases are progressively increasing but the number of reported cases is underestimated due to the lack of outbreak reports in the hospitals. ${ }^{5}$ So food safety measures should be applied in all settings and occasions in the 
community and particularly inside the hospitals. Food hygiene in the hospital is particularly important as many patients could be more vulnerable than healthy subjects to microbiological and nutritional risks. ${ }^{6}$

There are many international programs and guidelines for food safety such as Canadian food safety guidelines (2014), FAO/WHO guidelines (2009), and Australian program (2007). ${ }^{7,1,8}$ In Egypt, there is a national food safety guideline as a part of the national guidelines for infection control measures inside hospitals, for both the hospital kitchens and the food handlers. ${ }^{9}$

Despite significant efforts by food safety systems, there is a considerable burden of food borne illness. ${ }^{10}$

So, assessment of food safety measures inside hospital kitchens is of great concern as it may share in lowering the problem of nosocomial food borne outbreaks.

The general objective of the current study is to improve food safety in hospital kitchens (university and other governmental hospital kitchens) in Tanta city, Gharbia Governorate, Egypt by assessment of applied food safety measures in hospital kitchens and food handlers.

\section{Methods:}

Settings of the Study: This study was a cross-sectional study, which was carried out at Tanta university hospitals' kitchens(3 kitchens)and other governmental hospitals kitchens(6 kitchens including; El Menshawy, Chest, Ophthalmology, Psychiatric, Health Insurance, and Mabarrah Hospital kitchens).

Study Sample: All kitchens of Tanta University Hospitals and other governmental hospitals in Tanta city, Gharbia Governorate were the target group of the study, besides all food handlers working in them who agreed to share in the study and continued in it.

A pilot Study was carried out before starting data collection inside Psychiatric Hospital kitchen (it includes 6 food handlers and service 50-60 daily meals) o validate the adequacy of the designed checklist, estimate the time needed for filling checklist and assessment of each study subject, and determine the potential obstacles that might be met with during the execution of the study.

After analyzing the results of the pilot study, some items of the questionnaire were modified or simplified to be easily understood by the study subject.

Face and content validity were assessed for the tools used in this study.

The content validity of the study tools was measured to evaluate the individual items as well as the entire instrument as being relevant and appropriate to test what they wanted to measure. The experts (three professors of public health) were asked to evaluate the individual items as percentage and rate on a 4- point rating scale $(1=$ not relevant, $2=$ little relevant, $3=$ relevant, $4=$ relevant)

Content validity index (CVVI) of different items was measured as a percentage for each item in the tool and face validity was the average of the contents' percentages.

Reliability was assessed using Testretest: Alpha Cronbach's reliability coefficient was 0.980

Data Collection and Tools of the Study: Tool I: Observational Checklist. ${ }^{(9,11}$

Tool (I-a): Kitchens' Observational Checklist. Kitchens were observed by the researcher to fill the modified food safety guidelines observational check list which included the following items: Hospital kitchen design, course of work in the kitchen, foodstuffs starting from food receiving to final distribution, equipment and utensils, cleanliness of the environment, dealing with waste, 
security \& safety, and surveillance system for food and utensil safety, audit system (through recorded data).

Tool (I-b): Food handlers' Observational Checklist. Which included the following items:-wearing working clothes (uniform), washing hands in different occasions, behaviors that prevent contamination of food.

Tool (II) questionnaire for food handler ${ }^{9,11,12,13,14}$ Which included personal and work related data including: name, age, sex, name of hospital, nature of employment in the kitchen, shift of working and period of working in the kitchen (date of employment).

License, vaccination, history of suffering from certain diseases in the last three months, history of contact with a family member suffering from any diseases, recent History of suffering from food borne diseases, travelling, isolation, training, preemployment medical examination and routine investigations.

Through filling kitchen observational check list (Tool I-a), food handlers' observational checklist (Tool I-b) and the questionnaire sheet for food handlers(Tool II).Data were collected through:

Observation of both university and governmental kitchens as well, and the staff food handlers working there to fill Tool I-a and b observational checklists.

Interview with all food handlers to fill a questionnaire sheet (Tool II). This was done through four to six visits/ week in both morning and evening shifts.

Scoring of the observational checklist was done by scoring each positive point or answer by one (1) point and scoring each negative and non-applicable points or answers by zero (0) point. (This score made by the researchers)

Scoring of the questionnaire was done by scoring each positive point or answer by two (2) points and scoring each negative and non-applicable points or answers by one (1) point.

All the score numbers of each questionnaire sheet and checklist were summated to determine the total scores of the two pillars (yes, no) of study subjects. A subtotal sum of the scores was done for each element separately. The total score is measured for each tool used.

Leveling was done for checklist where every kitchen or food handler that achieved equal or more than three quarters of the total score $(\geq 75 \%)$ was considered sufficient (level 1), those achieved from one half to less than three quarters $(50 \%$ - $<75 \%)$ were considered somewhat sufficient(level 2) those achieved less than one half $(<50 \%)$ was considered insufficient(level 3). These levels made by the researchers according to commonly used levels of achievements.

\section{Statistical Analysis:}

The questionnaire and observational checklist forms were filled, a code sheet was developed; sorting, and tabulation and analysis of data were performed by using SPSS(statistical package for social studies)version 21.

Statistical significance for the differences between proportions was determined using the Chi-square test and fisher's exact test for qualitative data, $\mathrm{P}<0.05$ was adopted as the level of significance.

\section{Ethical consideration:}

The study was approved by Ethical Committee of the Faculty of Medicine; Tanta University. An official permission letter was obtained and directed to administrators of selected hospitals. Participants were informed about the purpose and procedure of the study and benefits of sharing in it.

\section{Results:}

The study included 9 hospital kitchens (3 university kitchens and 6 governmental kitchens) and all food handlers in these 
Table 1: Frequency of the applied main food safety measures in university and governmental hospital kitchens in both morning and evening shifts.

\begin{tabular}{|c|c|c|c|c|c|c|}
\hline \multirow{3}{*}{$\begin{array}{c}\text { Main items of kitchen } \\
\text { food safety items }\end{array}$} & \multirow{2}{*}{\multicolumn{2}{|c|}{$\begin{array}{c}\begin{array}{c}\text { University } \\
\text { hospital kitchen } \\
(\mathrm{n}=3)\end{array} \\
\text { Morning or Evening }\end{array}$}} & \multirow{2}{*}{\multicolumn{2}{|c|}{$\begin{array}{c}\begin{array}{c}\text { Governmental } \\
\text { hospital kitchen } \\
(\mathbf{n}=5)\end{array} \\
\begin{array}{c}\text { Morning or } \\
\text { Evening }\end{array} \\
\end{array}$}} & \multirow{3}{*}{$\begin{array}{l}X^{2} \\
\text { test } \\
\text { or } \\
\text { FE }\end{array}$} & \multirow{3}{*}{$\mathbf{P}$} \\
\hline & & & & & & \\
\hline & $\mathrm{n}$ & $\%$ & $\mathrm{n}$ & $\%$ & & \\
\hline -Hospital kitchen design & 2 & 66.7 & 5 & 100 & & 0.375 \\
\hline $\begin{array}{l}\text {-Course of work in the } \\
\text { kitchen }\end{array}$ & 0 & 0.0 & 4 & 80.0 & & 0.143 \\
\hline \multirow[t]{2}{*}{-Foodstuffs } & 3 & 100 & 4 & 80.0 & \multirow[t]{2}{*}{3.61} & \multirow[t]{2}{*}{0.165} \\
\hline & 1 & 33.3 & 4 & 80.0 & & \\
\hline -Equipment and utensils & 0 & 0.0 & 2 & 40.0 & & 0.464 \\
\hline $\begin{array}{l}\text {-Cleanliness of the } \\
\text { environment }\end{array}$ & 3 & 100 & 5 & 100 & & 1.000 \\
\hline \multirow{2}{*}{\begin{tabular}{ll|l}
-Dealing & wit & M \\
\cline { 2 - 3 } waste & & $\mathrm{E}$
\end{tabular}} & 1 & 33.3 & 4 & 80.0 & 5.08 & 0.079 \\
\hline & 0 & 0.0 & 4 & 80.0 & & \\
\hline -Security\& safety & 2 & 66.7 & 4 & 80.0 & & 0.464 \\
\hline $\begin{array}{l}\text {-Surveillance system for } \\
\text { food and utensil safety }\end{array}$ & 0 & 0.0 & 4 & 80.0 & & 0.143 \\
\hline $\begin{array}{l}\text {-Audit system } \\
\text { recorded data) }\end{array}$ & 3 & 100 & 5 & 100 & & 1.000 \\
\hline
\end{tabular}

FE=Fisher Exact test $\mathrm{M}=$ Morning $\quad \mathrm{E}=$ Evening

N.B: The percentage of all items in both morning and evening shifts are the same in governmental hospital kitchens. Items of hospital kitchen design: (ceiling, floors, walls, hand washing facilities, ventilation, lighting, water drainage system, and sewage disposal, presence of separate rooms for changing cloths of food handlers, bathrooms, pest control and proper surface area of kitchen. The change in morning and evening shifts present only in the items (food stuffs and dealing with waste)

kitchens (175) to assess the application of food safety measures in hospital kitchens.

The results of the current study revealed that:

1-Regarding hospital kitchens: There were no statistically significant differences in both university and governmental hospital kitchens in both morning and evening shifts, as regards all main elements. All university and governmental kitchens followed food safety measures regarding cleanliness of the environment and audit system in both shifts. Safety measures for kitchen design were completely followed in governmental kitchens as compared with only two thirds of university kitchens. None of university kitchens followed food safety measures regarding course of work in the kitchen, equipment and utensils, surveillance system and dealing with waste in evening shift. On the other hand, about four fifths of governmental kitchens followed food safety measures regarding course of work in the kitchen, foodstuffs, dealing with waste, security and safety and surveillance system (table 1).

All university kitchens had insufficient application of food safety measures in both morning and evening shifts. Regarding governmental kitchens, $40 \%$ were insufficient and $60 \%$ were somewhat sufficient in morning shift, but in the evening shift $60 \%$ of kitchens were insufficient and $40 \%$ of them were somewhat sufficient. There were no statistically significant differences neither between university and

\begin{tabular}{lllll}
\hline The Egyptian Journal of Community Medicine & Vol. 36 & No. 4 & October & 2018
\end{tabular}


Table 2: Levels of applied food safety measures conducted by food handlers in both university and governmental hospital kitchens.

\begin{tabular}{|c|c|c|c|c|c|c|c|}
\hline \multirow{2}{*}{\multicolumn{2}{|c|}{$\begin{array}{l}\text { Food handlers' checklist } \\
\text { items }\end{array}$}} & \multicolumn{2}{|c|}{$\begin{array}{l}\text { University } \\
\text { hospital food } \\
\text { handlers } \\
(n=99)\end{array}$} & \multicolumn{2}{|c|}{$\begin{array}{l}\text { Governmental } \\
\text { hospital food } \\
\text { handlers } \\
(n=76)\end{array}$} & \multirow[t]{2}{*}{$\begin{array}{l}\mathrm{X}^{2} \text { test } \\
\text { or } \\
\text { FE }\end{array}$} & \multirow[t]{2}{*}{$\mathbf{P}$} \\
\hline & & $\mathbf{n}$ & $\%$ & n & $\%$ & & \\
\hline \multirow{2}{*}{$\begin{array}{l}\text { Wearing } \\
\text { working } \\
\text { clothes } \\
\text { (uniform) }\end{array}$} & Insufficient & 13 & 13.1 & 41 & 75.9 & \multirow{2}{*}{40.85} & \multirow{2}{*}{$<0.001 *$} \\
\hline & $\begin{array}{l}\text { Somewhat } \\
\text { sufficient }\end{array}$ & 36 & 36.4 & 25 & 32.9 & & \\
\hline \multirow{3}{*}{$\begin{array}{l}\text { Washing hands } \\
\text { in different } \\
\text { occasions } \\
\text { (before and } \\
\text { after work, } \\
\text { dealing with } \\
\text { food, touching } \\
\text { hair) }\end{array}$} & Sufficient & 50 & 50.5 & 10 & 13.2 & \multirow{3}{*}{--} & \multirow{3}{*}{$<0.001 *$} \\
\hline & Insufficient & 99 & 100 & 68 & 89.5 & & \\
\hline & $\begin{array}{l}\text { Somewhat } \\
\text { sufficient }\end{array}$ & 0 & 0.0 & 8 & 10.5 & & \\
\hline \multirow{3}{*}{$\begin{array}{l}\text { Behaviors that } \\
\text { prevent } \\
\text { contamination } \\
\text { of food }\end{array}$} & Insufficient & 17 & 17.2 & 2 & 2.6 & \multirow{3}{*}{15.99} & \multirow{3}{*}{$<0.001^{*}$} \\
\hline & \begin{tabular}{|l|}
$\begin{array}{l}\text { Somewhat } \\
\text { sufficient }\end{array}$ \\
\end{tabular} & 50 & 50.5 & 30 & 39.5 & & \\
\hline & Sufficient & 32 & 32.3 & 44 & 57.9 & & \\
\hline \multirow{2}{*}{ Total } & Insufficient & 94 & 94.9 & 64 & 84.2 & \multirow{2}{*}{4.50} & \multirow{2}{*}{$0.040 *$} \\
\hline & $\begin{array}{l}\text { Somewhat } \\
\text { sufficient }\end{array}$ & 5 & 5.1 & 12 & 15.8 & & \\
\hline
\end{tabular}

governmental kitchens nor morning and evening shifts (Figure 1).

2-Regarding food handlers: Regarding wearing working clothes, about one half of food handlers in university kitchens were sufficient $(50.5 \%)$, but about three quarters in governmental kitchens were insufficient (75.9\%). The majority of food handlers were insufficient in washing hands in both university and governmental kitchens (100\% and $89.5 \%$ respectively). Regarding behaviors of food handlers that prevent food contamination, about one half in university kitchens were somewhat sufficient, but about one half in governmental kitchens were sufficient. The majority of food safety measures related to food handlers was insufficient in both university and governmental kitchens $\quad(94.9 \%$ and $84.2 \%$ respectively).There were statistically significant differences between wearing working clothes, washing hands and behaviors that prevent food contamination in both university and governmental hospitals $(\mathrm{p}<0.001)$ (table $3)$.

The total practice of university and governmental food handlers in relation to their characteristics were insufficient and somewhat sufficient with nonstatistically significant differences except for employment nature and receiving training among governmental food handlers $(\mathrm{P}=0.005$ and 0.0001$)$ 
Table 3: Relationship between total practice of the studied food handlers in both university and governmental hospital kitchens and their characteristics.

\begin{tabular}{|c|c|c|c|c|c|c|c|c|c|}
\hline \multirow{3}{*}{\multicolumn{2}{|c|}{$\begin{array}{l}\text { Characteristics of food } \\
\text { handlers }\end{array}$}} & \multicolumn{4}{|c|}{$\begin{array}{l}\text { University hospital kitchens } \\
(\mathbf{n}=99)\end{array}$} & \multicolumn{2}{|c|}{$\begin{array}{l}\text { Governmental } \\
\text { kitchens } \\
(\mathrm{n}=76)\end{array}$} & & hospital \\
\hline & & \multicolumn{2}{|c|}{$\begin{array}{l}\text { Insufficient } \\
(\mathrm{n}=94)\end{array}$} & \multicolumn{2}{|c|}{$\begin{array}{l}\text { Somewhat } \\
\text { sufficient } \\
(\mathbf{n}=5)\end{array}$} & \multicolumn{2}{|c|}{$\begin{array}{l}\text { Insufficient } \\
(n=64)\end{array}$} & \multicolumn{2}{|c|}{$\begin{array}{l}\text { Somewhat } \\
\text { sufficient } \\
(n=12)\end{array}$} \\
\hline & & $\mathrm{n}$ & & $n$ & & $\mathrm{n}$ & $\%$ & $\mathrm{n}$ & $\%$ \\
\hline \multirow[t]{3}{*}{-Age (years) } & $10-<25$ & 13 & 81.3 & 3 & 18.3 & 4 & 66.7 & 2 & 33.3 \\
\hline & $25-<40$ & 60 & 98.4 & 1 & 1.6 & 41 & 82.0 & 9 & 18.0 \\
\hline & $40-60$ & 21 & 95.5 & 1 & 4.5 & 19 & 95.0 & 1 & 5.0 \\
\hline$X^{2}(p)$ & & \multicolumn{5}{|c|}{$7.754(0.021 *)$} & \multicolumn{3}{|c|}{$3.324(0.190)$} \\
\hline \multirow[t]{2}{*}{-Sex } & Male & 16 & 94.1 & 1 & 5.9 & 32 & 82.1 & 7 & 17.9 \\
\hline & female & 78 & 95.1 & 4 & 4.9 & 32 & 86.5 & 5 & 13.5 \\
\hline $\mathrm{X}^{2}(\mathrm{p})$ & & \multicolumn{5}{|c|}{$0.030(0.863)$} & \multicolumn{3}{|c|}{$0.281(0.596)$} \\
\hline \multirow{2}{*}{$\begin{array}{l}\text {-Employment } \\
\text { nature }\end{array}$} & single & 6 & 85.7 & 1 & 14.3 & 2 & 40.0 & 3 & 60.0 \\
\hline & multiple & 88 & 95.7 & 4 & 4.3 & 62 & 87.3 & 9 & \begin{tabular}{|l|}
12.7 \\
\end{tabular} \\
\hline $\mathrm{X}^{2}(\mathrm{p})$ & & \multicolumn{5}{|c|}{$1.340(0.247)$} & \multicolumn{3}{|c|}{$7.868(0.005 *)$} \\
\hline \multirow[t]{3}{*}{$\begin{array}{l}\text {-Working } \\
\text { period(years) }\end{array}$} & $\begin{array}{l}\text { Less than } \\
5\end{array}$ & 46 & 93.3 & 3 & 6.1 & 33 & 80.5 & 8 & 19.5 \\
\hline & $5-<15$ & 39 & 95.1 & 2 & 4.9 & 20 & 83.3 & 4 & 16.7 \\
\hline & $15-30$ & 9 & 100 & 0 & 0.0 & 11 & 100 & 0 & 0.0 \\
\hline $\mathrm{X}^{2}(\mathrm{p})$ & & \multicolumn{4}{|c|}{$0.599(0.741)$} & & \multicolumn{3}{|c|}{$2.504(0.286)$} \\
\hline \multirow[t]{2}{*}{-Traveling } & Yes & 4 & 100 & 0 & 0.0 & 5 & 71.4 & 2 & 28.6 \\
\hline & No & 90 & 94.7 & 5 & 5.3 & 59 & 85.5 & 10 & 14.5 \\
\hline $\mathrm{X}^{2}(\mathrm{p})$ & & \multicolumn{4}{|c|}{$0.222(0.638)$} & & \multicolumn{3}{|c|}{$0.749(0.330)$} \\
\hline \multirow{2}{*}{$\begin{array}{l}\text { Receiving } \\
\text { training }\end{array}$} & Yes & 9 & 100 & 0 & 0.0 & 46 & 95.8 & 2 & 4.2 \\
\hline & No & 85 & 94.4 & 5 & 5.6 & 18 & 64.3 & 10 & 35.7 \\
\hline $\mathrm{X}^{2}(\mathrm{p})$ & & \multicolumn{4}{|c|}{$0.527(0.468)$} & & \multicolumn{3}{|c|}{$13.237(0.0001 *)$} \\
\hline \multirow{3}{*}{$\begin{array}{l}\text { sick leaves } \\
\text { duration }\end{array}$} & $3-<6$ & 0 & 0.0 & 0 & 0.0 & 2 & 100 & 0 & 0.0 \\
\hline & $6-<9$ & 0 & 0.0 & 0 & 0.0 & 0 & 0.0 & 0 & 0.0 \\
\hline & $9-12$ & 0 & 0.0 & 0 & 0.0 & 1 & 3.0 & 0 & 0.0 \\
\hline $\mathrm{X}^{2}(\mathrm{p})$ & & (1.) & & & & & $0.591(0.2$ & 44) & \\
\hline
\end{tabular}

Employment nature: we mean multiple work tasks which are overload on workers and can affect their performance. Traveling: for expectation of carrying infection from another country. Sick leaves duration: Indicate severity of disease and possibility of transmission of infection to patients

respectively, and among age distribution in university food handlers (0.021) (table 4).

\section{Discussion:}

Outbreaks of food borne infections in hospitals are preventable. ${ }^{15}$ Adherence to food safety measures among food services staff in hospitals is vital for the prevention of food borne outbreaks. ${ }^{16}$
Food safety is therefore of growing concern in hospitals. ${ }^{17}$

Food Safety Measures in Hospital Kitchens:The present study reported that, all food safety measures in university kitchens were insufficient. Regarding governmental kitchens, about $60 \%$ of kitchens were somewhat sufficient in morning shift but were insufficient in evening shifts. This may be due to most of university kitchens had bad 
infrastructure ,most of works were done manually (no enough machines) , university' food handlers are temporary workers in the kitchens (no paid sick leaves, very low salary, no health insurance), no training courses for food handlers, and lack of qualified and

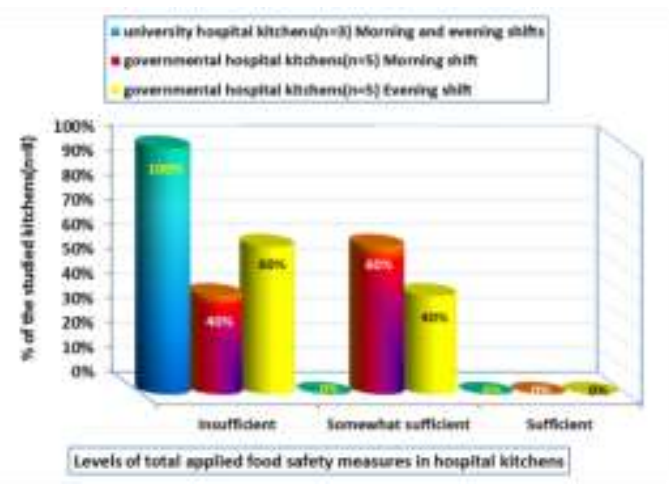

Figure1: Levels of total applied food safety measures in both university and governmental hospital kitchens.

experienced supervisors. While, in the governmental kitchens, most of them follow guidelines for food safety, food handlers are permanent employee in the hospitals, most of works were done by machines, most of food handlers took training courses but not enough, infrastructure need some development and in the evening shift there were not enough supervision.

In accordance with the present study, results that found by Mehrdad et al, in Shiraz, Iran (2004) who reported that only $35.5 \%$ of hospitals had adopted food safety practice manuals and $61 \%$ had developed personal hygiene procedures. ${ }^{18}$ On the contrary, in USA (2014), Andrew et al in their study among hospitals, reported that industrial risk management strategies and food safety measures in the hospital kitchen appear sufficient to minimize risk to food handlers, hospital staff and patients and prevent spread of infection to them. ${ }^{19}$

Regarding kitchen design, about two thirds of university kitchens and governmental kitchens had insufficient design in both shifts as infrastructure needs some development, poor ventilation and lightening due to improper distribution of both windows and doors and lack of air conditioning system. These results were in accordance with, CilceBertin et al, in Brazil (2009) who reported that the examined hospital kitchens had unhealthy environmental conditions with high temperature, high humidity due to poor ventilation, kitchens were with restricted area. $^{20}$ All these conditions increased probability of errors and had harmful effects on food handlers. This is similar to what found by a study in Japan by Matusuzuki H etal, (2012). ${ }^{21}$

Regarding food stuffs, all university kitchens followed food safety measures in the morning shift and only $33.3 \%$ of kitchens in the evening shift due to lack of complete supervision and experienced supervisors compared to 80\% of governmental kitchens in both shifts. All university kitchens were insufficient in both shifts but $60 \%$ and $20 \%$ of governmental kitchens were somewhat sufficient in both morning and evening shifts respectively. This may be due to ignorance of food handlers, lack of mechanization, preparation of several types of food in the same place, no washing of fruits, no wearing gloves during washing vegetables and thawing of freezed chickens at room temperature. In accordance with this study regarding food preparation, Hartwell et al in England (2001) in their study reported that poor food preparation and storage facilities which in turn led to a complete failure by staff to follow basic rules of food safety practices. Subsequently, an outbreak of food poisoning occurred ${ }^{(22)}$. Regarding the process of food distribution, there was no immediate cooling of cooked food in the present study as distribution occurs immediately after cooking. 
In accordance, EL Derea et al study (2008) there was no equipment for rapid cooling of cooked meat that result in food poisoning outbreak ${ }^{(23)}$.In Japan (2012) Matusuzuki H et al study reported that there was a problem in food distribution that was done by normal wagon. The temperature of meals and food must be kept over $60^{\circ} \mathrm{c}$ or below $10^{\circ} \mathrm{C}$, so introduction of hot and cold holding wagons was necessary. ${ }^{21}$

Regarding equipment and utensils, none of university kitchens followed safety measures compared to $40 \%$ of governmental ones. This is due to all utensils are made of aluminum in university kitchens and most of governmental kitchens. No following ideal steps of washing utensils manually due to lack of knowledge of food handlers and supervisors and lack of enough basins and used disinfectant for washing. No safety measures followed regarding refrigerators in university kitchens and minority of governmental kitchens as it had no adequate space, no thermometer and sometimes contain personnel food due to ignorance of workers and lack of supervision.

A study performed in Brazil (2009) reported that there were lack of equipment and utensils in the hospital kitchen, forcing food handlers to use incorrect procedures. $^{20}$ Similarly, a study which was done in Egypt (2008) reported that equipment and utensils parameter had the lowest score $(40 \%$ and $63.3 \%)$ in two hospitals in Alexandria (Gamal Abdel Nasser hospital and Medical Research Institute) before and after a food safety training program. Utensils used in the hospitals were made of aluminum. Also, poorly cleaned utensils and equipment surfaces harbor and promote the spread of microorganisms. ${ }^{23}$

Regarding clean environment, all university and governmental kitchens followed safety measures. Only 20\% of governmental kitchens were sufficient compared to none of university kitchens. These results can be explained by lack of guidelines for cleaning schedule in university kitchens and lack of its application in governmental kitchens, and lack of complete supervision in both hospitals.

In agreement with this study, Theron et al, in South Africa (2007) reported that a formal cleaning schedule was not in place in all hospital kitchens, as $8 \%$ of food handlers indicated that they "cleanas-they-go." It was reported that surfaces were only cleaned and washed after a day's work for twenty-four hours (24).Similar findings was proved by EL Derea etal, in Egypt (2008), Anderson etal, in USA (2004), and Jay etal,(2000) in Australia. ${ }^{23,25,26}$

As regards waste management (regular waste disposal, safety measures when dealing with oily residues, waste containers controlled by foot and contain black plastic bag and clean baskets) only one third of university kitchens followed safety measures with somewhat sufficient level of application in the morning shift compared to $80 \%$ of governmental kitchens in both shifts, as governmental kitchens had protocol and guidelines for food safety. Ahmed et al, (2014) in their study in Khartoum State Hospital showed lack of comprehensive waste disposal plans for the disposal and technical aspects of hazardous waste in hospitals. ${ }^{27} \mathrm{He}$ attributed this to lack of prober guidelines, legislation, regulations, and instructions on health care waste management particularly issues covering segregation, collection, and disposal of various categories of waste in suitable manner to render it harmless.

Regarding security and safety, about $66.7 \%$ of university kitchens followed safety measures with somewhat 
sufficient level compared to $80 \%$ of governmental kitchens in both shifts, also somewhat sufficient. Most of university and governmental kitchens followed safety measures regarding containment of any malfunction by industrial safety or engineering department. These findings were better than that reported in study in Brazil (2009) that was performed to assess hurdles at work. They found that equipment were out of service due to lack of maintenance thereby causing extra work and delay in meal delivery. ${ }^{20}$ In the current study, all university and governmental kitchens had limited access of non-essential personnel to kitchens. On the contrary, a Brazilian study (2009) found that more serious situation was that strangers to the department were present and there was no limiting access of non-essential personnel. ${ }^{20}$

As regards course of work, surveillance and audit system,

Regarding course of work in kitchen and surveillance, none of university kitchens were sufficient compared to $80 \%$ of governmental kitchens and all kitchens were sufficient in audit system in both shifts. This may be attributed to the better infrastructure than university kitchens and MOHP had continuous supervision on governmental kitchens. These findings were in accordance with The National guide for infection control (2008) and Canadian food safety guidelines (2014). ${ }^{9,7}$

Regarding the course of work, Aston (2000) reported that once foods leave the confines of the kitchen, food safety was out of the control of the caterers. A number of personnel were involved and effective coordination needed to be in place to ensure that food was appropriately controlled and monitored throughout the distribution chain ${ }^{(28)}$.

Food Handlers Practices of Food Safety Measures:In the present study, the majority of food safety measures conducted by food handlers were insufficient in both university and governmental kitchens, these results refer to the lack of complete supervision, financial resources, and knowledge of food handlers and sometimes reluctance of food handlers about importance of wearing working clothes or uniform.

Regarding wearing working clothes, about half of food handlers in university kitchens applied sufficient food safety measures (disposable gloves, overhead), but about three quarters in governmental kitchens were applied safety measures regarding working clothes with insufficient level. This may be due to lack of supervision, lack of financial resources, lack of knowledge, and reluctance of food handlers to wear working cloths.

In Calabria, Italy (2000) Angelillo et al reported in their study that only $20.8 \%$ used gloves when touching unwrapped raw food, and predictors of their use were educational level and attending education courses. In another study, the researcher reported that only $54.9 \%$ of those involved in touching or serving unwrapped raw or cooked foods routinely used gloves during this activity. ${ }^{21}$

The majority of food handlers were insufficient in washing hands in both university and governmental kitchen.. Most of university and governmental kitchens had no hand washing facilities that equipped with liquid soap and disposable paper towels. Food handlers were not trained on ideal hand washing and its importance in different occasions and there was a lack in complete supervision and experienced supervisors. In accordance with the present work, Anderson et al, in USA (2004) reported in their study that hand washing was inadequate and only one-third of subjects 'hand wash attempts were with soap. ${ }^{25}$ 
Regarding behaviors of food handlers that prevent food contamination (rubbed the nose and ears and touched the hair during work, wore jewelry at work) half in university kitchens were somewhat sufficient, but more than one half in governmental kitchens were sufficient. Jay et al, in Australia (2000) in their study reported that touching of the face, mouth, nose, and/or hair by food handlers during food preparation, and lack of separate hand and dishtowels were the most common unhygienic practices observed. ${ }^{26}$

Food Handlers' characteristics and their Practices. The age group $19-<25$ years had more sufficient practice than the older ages as they were more active, with statistically significant differences between university food handlers. A majority of males and females had insufficient total practice in university kitchens and in governmental kitchens.

On the contrary, a survey was conducted in Shiraz, Iran (2004) the researchers reported in their study that females practiced safety measures less often than did males. Also, older personnel had better practices ${ }^{(18)}$.

Food handlers who had multiple work tasks had insufficient total practice in both university and governmental kitchens as they did not have enough time to do each work separately.

All food handlers who worked for period ranged from 15-30 years had insufficient total practice. In fact, long periods of work gains more skilled food handlers in cooking but not necessarily skilled in food safety measures. University food handlers who travelled abroad had more insufficient total practice than who did not travel but governmental food handlers who did not travel had more insufficient practice than who travelled, with no statistically significant difference.
University and governmental food handlers who received training had more insufficient total practice than who did not receive. This can be explained by that food handlers did not understand the aim of training courses or training topics may be ineffective. Mehrdad et al (2004) reported in their study that there is a need for education and increased awareness among food service staff regarding safe food handling practices ${ }^{18}$

In Egypt, El Derea (2008) reported that food safety practices in two hospitals in Alexandria improved after the training program. All food handlers who had sick leave less than three months in university kitchens and 3-<6 months in governmental kitchens had insufficient total practice. This may be explained by deterioration of health that has negative impact on the practice. ${ }^{23}$

\section{Conclusion and recommendation:}

The study found insufficient conduction of food safety measures in both university and governmental hospital kitchens as well as insufficient application of food safety measures by food handlers. This revealed that patients are at risk of getting food borne infections. So conduction of pre-service and in-service training program, development of food safety committee and team, continuous supervision, improving kitchens infrastructure and work environment, presence of food safety guidelines manual were recommended.

\section{References}

1. FAO/WHO (2009) The Food and Agriculture Organization of the United Nations (FAO) and the World Health Organization, Food hygiene, basic texts4thed.Available at http://www. fao.org/ docrep/012/ a1552e/a1552e00.pdf, accessed at $9 / 6 / 2014$. 
2. Sydnor ERM, and Perl TM(2011) Hospital Epidemiology and Infection Control in Acute-Care Settings, Clinical Microbiology Reviews, 24(1), , pp. 141-173. 3. Nyachuba DG (2010) Food borne illness: is it on the rise? Journal of Nutrition Reviews; 68(5):257-69

4. AhramOnline (2013) Food poisoned students released from hospital 25 May 2013.Available

http:/English.ahram.org.eg/, access date at 7/6/2013

5. Redmond EC, and Griffith CJ, (2003) Consumer food handling in the home: a review of food safety studies, International Association for Food; Journal of Food Protection, 66(1): pp.130-161.Available at http://www.ncbi.nlm.nih.Gov/pub med/12540194, access date at 30/8/2013.

6. Buccheri C, Casuccio A, Giammanco S, Giammanco M, La Guardia M, and Mammina C (2007) BMC Biomed central Health Services Research, Palermo University: Food safety in hospital: knowledge, attitudes and practices of nursing staff of two hospitals in Sicily, Italy" 7:45. Available

at

http://www.biomedcentral.com/1472-

6963/7/45, access date 15/3/2014.

7. Canadian Food Inspection Agency (2014) Food Safety Enhancement Program.Canadian food safety Guidelines. Available at http://www.inspection.gc.ca/ food/ action-plan/ food-safety-regulatoryforum/eng/ $1369676743621 /$ 1369676873558, access date 12/1/2014.

8. Australia New Zealand (2007) Food standard code (Australia only).Food Safety Programs", A guide to standard 3.2.1. 3(1):59 .Available at http://www.foodstandards.gov.au.Access date at 30/8/2013.

9. Ministry of Health and Population (MOHP), Egypt (2008) National Guide For Infection Control", Health Programs. Available at

http://www.mohp.gov.eg/programs/Infect Fight/defaulta.spx, access date 30/8/2013.

10. Havelaar AH, Brul S, De Jong A, de Jonge R, Zwietering $\mathrm{MH}$ and TerKuile Food Microbiology, 139 (1):79-94.Available at http://www.ncbi.nlm.nih.gov/ pubmed/19913933, access date at 15/3/2014. 11. Barron FH (2002) Food Safety Inspections: Basic Compliance Checklists for GMPs(Good Manufacturing Practices (GMPs), SSOPs(Sanitation standard operating SOP's)and HACCP(Hazard Analysis Critical Control Point).Clemson University South Carolina, United States.Department of Food Science and Human Nutrition,. Available at http://www.clemson.edu/visit/,access date $15 / 8 / 2013$.

12. University of Essex, London (2010) Occupational Health Service Food Handling Health Questionnaire. Available at http://www .essex.ac.uk .com, access date 21/9/2013

13. University of Leeds, England, Occupational health service (2010) Protocol for Food handlers; Journal of Western Pacific Surveillance and Response, 9 November.

14. University of Northampton, United Kingdom, human resources (2009) Supplementary questionnaire for food handlers, occupational health and safety office. Available at http://www.Northampton.ac.uk.Food_Handli ng_Questionnaire.com, access date 20/9/2013.

15. Custovic A, Ibraimagic O (2005) Prevention of food poisoning in hospitals. Medicinski arhiv Journal;9(5):3035.Available at www.ncbi. Nlm.nih.gov/pub med/16134753 accessed date at 13/7/2014

16. Askarian M, Kabir G, Aminbaig M,Memish ZA, and Jafari P. (2004) Knowledge, attitudes, and practices of food service staff regarding food hygiene in Shiraz, Iran. Infection control and hospital epidemiology; 25(1):16-20.

17. Council of Europe (2001) Food and Nutritional Care in Hospitals: How to Prevent Under nutrition. Clinical Nutrition Journal; 20(5):455-60.

18. Mehrdad A, Aminbaig M, Ziad A, and Jafari P (2004) Knowledge ,attitude and practices of food service staff regarding food hygiene in Shiraz ,Iran", Infection control and hospital epidemiology, 25(1):16-20. 
19. Stewardson A, J, Renzi G, Maury N, Vaudaux C, Brossier and Fritsch E (2014) Society for Healthcare Epidemiology of America: Hospital food safety measures reduce risk of contaminated hospital food", Infection Control and Hospital Epidemiology, 35 (4)375.

20. Bertin $\mathrm{CH}$, Rezende MA, Sigulem DM, and Morais TB (2009) Hurdles at work perceptions of hospital food handlers. Human Resources for Health 24 7:63.Available at www.human-resourceshealth.com/ content/7/1/63, accessed at 7/6/2014.

21. Matusuzuki H, Haruyama Y, Muto T, Aikawa K, Ito A and Katamoto S (2012) Workers' load and job -related stress after a reform and work system change in a hospital kitchen in Japan", Environmental health and preventive medicine ; 18, pp.171-176.

22. Hartwell H, and Edwards J (2001)A preliminary assessment of two hospital foodservice systems using parameters of food safety and consumer opinion", The Journal of the Royal Society for the Promotion of Health, 121(4)236242.Available at http://rsh.sagepub.com/content/121/4/236.

23. El Derea H, Salem E, Fawzi M and Abdel Azeem M(2007) Safety of patient meals in 2 hospitals in Alexandria, Egypt before and after training of food handlers. Eastern Mediterranean Health Journal;14 (4):941-52.

24. Theron MM (2007) The personnel and general hygiene practices of food handlers in the delicatessen sections of retail outlets in South Africa 1-7.

25. Anderson JB, Shuster TA, Hansen KE, Levy AS, and Volk A (2004) A camera's view of consumer food-handling behaviors. Journal of American Diet Association, 104 (2):186-191.

26. Jay LS, Comar D, and Govenlock LD (2000) A video study of Australian domestic food-handling practices. Journal of Food Protection, 62:1285-1296.

27. Ahmed NO, Gasmelseed GA and Musa AE (2014) Assessment of Medical Solid Waste Management in Khartoum State Hospital. Journal of Applied and industrial Sciences (2014); 2(4):1-5

28. Aston G (2000) Food hygiene in hospitals-are we training the right people? Journal of Society Health 120 (4):211.

29. Angelillo I.F, Viggiani NM, Rizzo L. and Bianco A (2000) Food handlers and food borne diseases: knowledge, attitudes, and reported behavior in, Italy. Journal of Food Protection, 63 (3):381-385. 